\title{
OLHARES SOBRE O AMBIENTE EM DIFERENTES MOMENTOS DE
} ESCOLARIZAÇÃO

\author{
The looks above the environment in diferente moments of schooling
}

\author{
André Ribeiro de Santana ${ }^{l}$ \\ Silvia Nogueira Chaves ${ }^{2}$
}

\section{RESUMO}

Nesta pesquisa narrativa, objetivamos caracterizar concepções de ambiente de 181 discentes vivenciando Ensino Fundamental ( $5^{\mathrm{a}}$ e $8^{\mathrm{a}}$ séries), Ensino Médio ( $3^{\circ}$ ano) e Ensino Superior $\left(4^{\circ}\right.$ e o último semestres de Pedagogia), averiguando ainda possíveis distinções de complexidade. $\mathrm{O}$ instrumento aplicado foi um questionário. A análise das respostas evidenciou que concepções de ambiente são representações sociais, por estarem, simultaneamente, na base da elaboração de comportamentos e da comunicação interpessoal, expondo experiências e valores culturais socialmente configurados. Percebemos predominância de dois entendimentos entre os sujeitos, influenciados pela práxis escolar e pela mídia: o ambiente onde vivo, estou e vou, cenário das interações do Homo sapiens entre si e com os demais componentes do ambiente; o manancial de vida, fonte dos elementos que asseguram o existir. Dessas concepções, emergem duas categorias: o ambiente universal, cujos limites podem extrapolar a atmosfera terrestre, sendo pleno de paz e harmonia e configurado por todas as relações entre os diversos integrantes ambientais; o ambiente do homem, substrato de nossa existência, composto por cidades, casas, escolas, praças e ruas. As inter-relações entre os dois ambientes são mediadas por cultura e tecnologia. Constatamos intenso antropocentrismo nos sujeitos, que se julgam privilegiados por serem da espécie capaz de decidir o destino do ambiente. Tais achados podem contribuir, simultaneamente, na Educação Ambiental e na Educação em Ciências, voltadas à busca do equilíbrio de nossas relações com os demais integrantes ambientais.

Palavras - chave: ambiente, concepções, educação ambiental, educação em ciências
ABSTRACT
In this narrative research, we aimed to characterize conceptions of environment of 181 students in the Fundmental Teach $\left(5^{\mathrm{a}}\right.$ and $8^{\mathrm{a}}$ grades), medium teach ( $3^{\circ}$ grade) and at university $\left(4^{\circ}\right.$ and the last semester of pedagogy), verifying possibles distinctions of complexity. The instrument applied was a questionary. The analysis of the answers noticed that conceptions of environment are social representations, because they are, at the same time,

\footnotetext{
${ }^{1}$ Mestre em Educação em Ciências. SEDUC/GPEAA-NPADC. mestredeo@yahoo.com.br

2 Doutora em Educação. UFPA. schaves@ufpa.br

AMAZÔNIA - Revista de Educação em Ciências e Matemáticas V.6 - n. 11 - jul. 2009/dez. 2009, V. 6 - n. 12 - jan 2010/jun. 2010
} 
in the base of behaviors and interpersonal communication, exposing experiences and cultural values socially configured. We realized the predominancy of two beliefs between the subjects, influenced by the scholar praxis and bay midia: the environment where I leave, I am and I'll go, the scene of interactions between the homo sapiens with himself and with other components of the environment; life manancial, source of the elements that ensure the existence. From those conceptions, it appears two categories: the universal environment, whose limits may extrapolate the land atmosphere, being plain with peace and harmony and configured by all the relations between many environmental members; the man's environment, product of our existence, fored by culture and technology. We noticed intense anthropocentrism in the subjects that find themselves privileged for being the especie capable of deciding the environment's destiny. Those may help both, environment education and science education, turned to the relations between us and the other environmental integrants.

Keywords: environment, conceptions, environmental educations, Science educations.

\section{INTRODUÇÃO}

\section{Contextualizando os porquês de estudar concepções ambientais}

Ao analisarmos trabalhos de temáticas conceituais referentes à ambiência (BRASIL, 2001; CABRAL, 2000; DIAS, 1991; CRESPO, 2003; GUIMARÃES, 2000; MEYER, 1991; PENTEADO, 1997; PIMENTEL \& BORDEST, 2003; REIGOTA, 1996, 2002; TRIGUEIRO, 2002, 2003), constatamos predomínio da visão antropocêntrica em abordagens ambientais, enfatizando-se um utilitarismo na linha do: "precisamos conservar o ambiente ${ }^{3}$ porque ele se presta à satisfação de nossas necessidades, criaturas divinamente privilegiadas posicionadas num espaço à parte" (THOMAS, 1988; VERNIER, 1998; VIEIRA, 2001).

Neste contexto, há uma diversidade de investigação referentes à percepção ambiental: desde ecofeministas cariocas (ARRUDA, 2000), estudantes do Ensino Fundamental (BONOTTO, 2000), estudantes do Ensino Médio (SANTANA et al, 2003; GUIDO, 2003), professores (CHINEN, 1999; FONTANA et al, 2002; OKAMURA, 1999), contudo, excetuando-se a pesquisa de opinião pública com a população brasileira (BRASIL, 2001) ${ }^{4}$, não encontramos nenhum trabalho averiguando, de modo comparativo, concepções de ambiente, por exemplo: comparando representações ambientais de crianças, adolescentes e adultos, ou mesmo de estudantes em diferentes fases de sua escolarização. Isto nos conduziu a seguinte questão: Quais as concepções de ambiente reveladas por estudantes em diferentes momentos do processo de escolarização?

Levando em conta que ao interagirmos com o ambiente o individualizamos como algo subjetivo e pessoal, caracterizar concepções de ambiente presentes em alunos de diferentes níveis de escolarização - aspecto extremamente relevante em nossa existência -, e investigar

\footnotetext{
3 Empregaremos esta palavra, pois concordamos com Coimbra (1985), para o qual o termo meio ambiente é redundante pois ambiente já inclui a noção de meio. Segundo este autor, esta redundância só existe nas línguas portuguesa e espanhola.

4 Desenvolvida no Brasil, a partir de 1992 (pré Eco-92), com repetições em 1997 (por ocasião da Rio+5) e 2001 (vésperas da Conferência de Joanesburgo), sob encomenda do Instituto de Estudos da Religião (Iser), patrocinadas pelo Ministério do Meio Ambiente, tendo como objetivo determinar o que o brasileiro pensa de meio ambiente. Nesta pesquisa, realizou-se estudo comparativo, considerando-se aspectos como os componentes do ambiente, os principais problemas ambientais e suas diversificações por conta das peculiaridades das cinco regiões brasileiras e dos níveis de escolaridade dos entrevistados (CRESPO, 2003; TRIGUEIRO, 2002). 
possíveis distinções de complexidade, podem propiciar elementos para ações e discussões eficazes em ocasionar mudanças no posicionamento ante aquilo que nos compõe/envolve.

\section{Caminhos metodológicos: como e porquês}

Havia necessidade de um instrumento que oportunizasse aos sujeitos expressarem sua subjetividade. Entretanto, como coletaríamos os dados nos próprios ambientes de escolarização, já que poderíamos encontrar turmas numerosas? Por conta dessa situação, concordamos que um questionário se adequaria ao número de sujeitos, sem impedir, dentro de limitações - como redução/ausência de interações dialogadas - a exposição de peculiaridades associadas ao entendimento ambiental..

Como subsidio na estruturação do questionário, selecionamos trabalhos de Sauvé (1994, 2002), nos quais temos concepções ambientais paradigmáticas: o ambiente original, puro, sem pessoas é o ambiente como natureza; quando o ambiente é retratado como algo gerenciável, relacionado ao Desenvolvimento Sustentável, é concebido como recurso; se há urgência em apreender estratégias de preservação e manutenção da qualidade do meio, tem-se ambiente como problema; caso a ênfase recaia em ecossistemas, relações ecológicas e desequilíbrios dissociados do homem, temos ambiente como sistema; se considerarmos aspectos sócio-culturais, históricos e tecnológicos contidos em elementos cotidianos - escola, vizinhança, trabalho, lazer - há o ambiente como lugar para se viver; existe ainda a possibilidade de entender a Terra como colossal organismo auto-regulável, ou o ambiente como biosfera; finalmente, quando se considera que a coletividade humana, com fatores como solidariedade, democracia e envolvimento individual e coletivo, caracteriza o ambiente, este é concebido como projeto comunitário.

Elaboramos questões direcionadas para que nossos discentes respondessem o que entendem por ambiente, quais seus integrantes, quais seus componentes mais relevantes, se acham o ambiente importante e o motivo. Fornecemos a opção de responderem através de desenhos. Carece ressaltar que as perguntas foram pensadas para serem complementares, propiciando extrair informações não atingidas em uma única indagação. A intenção final era, a partir da interpretação da totalidade das respostas, extrair a concepção ambiental do informante com o máximo de plenitude permitida pelo recurso empregado. No total, obtivemos informações de 181 sujeitos ${ }^{5}$.

Conceituações pessoais advém de subjetivações diante das nuances da realidade, vivenciada de modo diferenciado conforme a autonomia no ir e vir, expectativas, projetos e interesses individuais. Obviamente crianças, adolescentes e adultos diferem nesses aspectos, o que justificaria coletar informações em séries espaçadas, uma providência reforçada pelas especificidades da $5^{\mathrm{a}}$ e $8^{\mathrm{a}}$ séries do Ensino Fundamental, do $3^{\circ}$ ano do Ensino Médio e do $4^{\mathrm{o}}$ e do último semestres de Graduações em Pedagogia ${ }^{6}$, os momentos de escolarização escolhidos.

Carece evidenciar que professores com os quais crianças travam contato no começo de sua escolarização, que pode preceder a $5^{\mathrm{a}}$ serie em, pelo menos, quatro anos, advém, usualmente, de formação generalista. Logo, suas compreensões de ambiente certamente foram influenciadas pela práxis de profissionais procedentes do Magistério em nível médio ou de cursos de Graduação, notadamente Pedagogia. Portanto capturar o entendimento ambiental

\footnotetext{
${ }^{5}$ Divididos entre 49 de $5^{\mathrm{a}}$ série, 51 de $8^{\mathrm{a}}$ série, 35 do $3^{\mathrm{o}}$ ano, 34 do $4^{\mathrm{o}}$ semestre e 12 concluintes de Pedagogia.

${ }^{6}$ Coletamos dados entre doze alunas concluintes, matriculadas em um Curso de Pedagogia, em regime especial (duração de dois anos) ofertado por uma Instituição Privada. Visando a ampliar, e diversificar, o quantitativo de discentes do ensino superior, coletamos, por impossibilidade de retorno à primeira instituição, dados de 34 alunos de quarto semestre, discentes de um curso regular de Pedagogia (duração de quatro anos) de uma instituição pública de Ensino Superior. 
desses docentes, dentro das possibilidades disponibilizadas pelo instrumento que empregamos, configura um fechamento de ciclo, refletindo-se em um perfilamento de concepções vinculadas a Educação Básica e Superior.

Ao analisar os dados, estabelecemos intercâmbios entre os conteúdos presentes nos retornos dos informantes com trabalhos proponentes de representações de ambiente (FONTANA, 2002; SAUVE, 1994; 2002), procurando captar, de modo critico, os sentidos presentes nos seus escritos e desenhos, bem como significados explícitos ou subliminares, evidentes ou ocultos (CHIZZOTI, 1991), ou seja: alem de apreender o sentido evidente da comunicação, precisamos atentar para o teor apenas entrevisto (BARDIN, 1977) nos retornos de nossos informantes, por exemplo: a presença humana subentendida num grafismo pela presença de latas de lixo, evidenciando também intenções de zelo, cuidado.

Buscamos, dentro do espectro de informações disponibilizadas por nossos informantes, extrair características que oportunizassem categorizar suas concepções de ambiente. Inicialmente, examinamos os questionários um de cada vez, buscando propriedades que permitissem diferencia-los entre si (ATLAN, 1990); em seguida, reunimos os dados que compartilhassem diferenças em grupos, iniciando a categorização. Deste modo, a ênfase em priorizar elementos não antrópicos nas respostas, simultaneamente a valoração de sua importância em assegurar a vida como um todo, ou a humana, em particular, nos conduziu a proposição de uma concepção de ambiente; caso o elemento enfatizado pelos sujeitos ${ }^{7}$ fosse o entorno, salientado em posicionamentos como ambiente " $E$ tudo aquilo que está ao nosso redor. ${ }^{\mathrm{GP} 1}$ " outra concepção seria estruturada, e assim por diante.

Tivemos de lidar com entendimentos diferenciados de ambiente, por vezes incoerentes. Se para alguns ambiente "É o ecossistema e o ambiente sócio-cultural "GP2 ", algo evidenciador de uma percepção mais holística, há sujeitos que enfatizam que ambiente é onde tem "Muitas árvores, muitos animais e também muitos frutos ${ }^{5^{a}}$ ", revelando um entendimento centrado em Natureza e ecologia. Um mesmo sujeito pode afirmar que ambiente "é tudo o que faz parte da natureza que nos rodeia $5^{5}$ " e citar como exemplos "A área de minha casa, a sala de aula, um campo de futebol $l^{a}$. "Isso nos levou a buscar unicidades, em meio a posicionamentos diversificados, detectando possíveis explicações.

Após avaliarmos características inerentes às concepções apresentamos o ambiente estruturado, a partir do ideário dos estudantes, pois entendemos que "...O que temos no pensamento são ideias... apenas ideias de porcos e coqueiros, de pessoas e seja lá o que for." (BATESON, 1990), logo suas representações traduzem um ambiente apreendido do real, e que carece ser conhecido.

\section{Sobre o ambiente harmoniosamente idealizado}

A análise dos posicionamentos dos sujeitos às indagações contidas no questionário permitiu constatar posicionamentos. Para a maioria dos informantes, ambiente ${ }^{8}$ é, essencialmente, natureza idílica, plena de harmonia, sem espaços para relações desarmônicas ou degradações. Neste contexto, temos um cenário de enorme amplitude, composto por florestas, rios e outros ecossistemas, capaz de abrigar as sofisticadas elaborações humanas, como cidades, culturas e ações, revelando-se generoso em fatores

\footnotetext{
7 As falas serão reproduzidas obedecendo ao seguinte padrão de identificação: após as mesmas, acrescentaremos, de forma sobrescrita, referindo-nos, respectivamente a $5^{\mathrm{a}}$ série, $8^{\mathrm{a}}$ série, $3^{\circ}$ ano, graduandos de $4^{\circ}$ semestre e concluintes de graduação os símbolos $5^{\mathrm{a}}$, $8^{\mathrm{a}}$, C, GP 1 e GP2.

${ }^{8}$ Nossos informantes usualmente empregam o termo ambiente para referirem-se aos espaços naturais, com freqüência, empregando exemplos e definições calcados em fatores ecológicos; quando se referem a ambientes alterados particularizam-nos com exemplos como casas, ruas, escolas ou adjetivam-no: familiar, escolar, de trabalho, lazer. 
mantenedores de um bom viver. Assim sendo, os rios são piscosos, as árvores frutíferas, e os animais belos e dóceis, sendo todos estes elementos usualmente configurados, nas vozes discentes, como recursos para a satisfação das nossas necessidades, quase que se ofertando espontaneamente ao nosso consumo. Isso tudo é bem evidenciado nas imagens geradas pelos estudantes, nas quais quase sempre fulgura um Sol radiante num céu límpido, com poucas nuvens, agraciado por revoadas de pássaros, como mostra um desenho de aluno de $5^{\mathrm{a}}$ série:

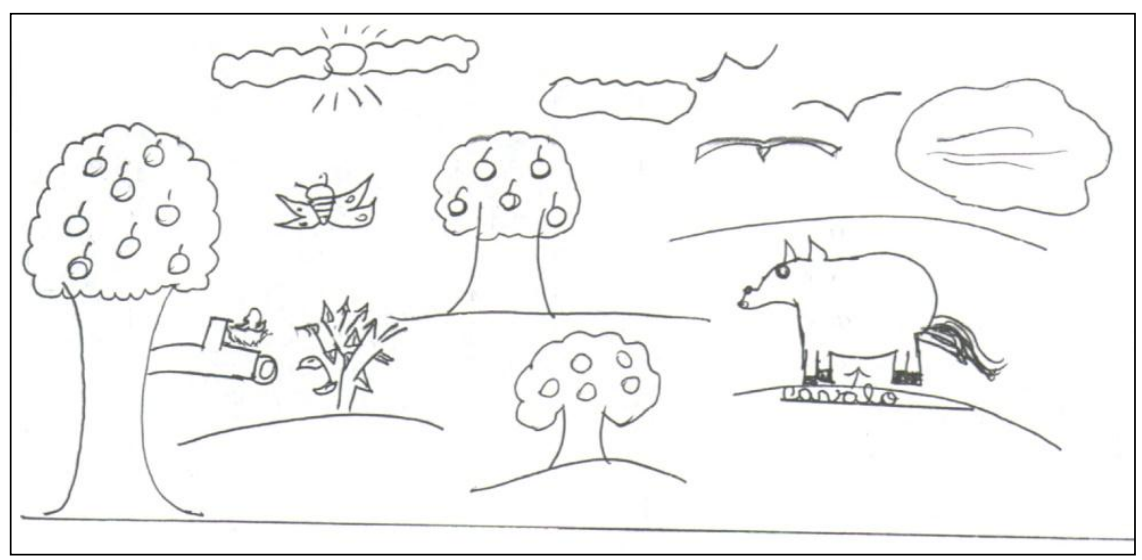

Nesses desenhos visualizamos um ambiente natural, extremamente espaçoso, a semelhança do bíblico Jardim do Éden, no qual impera a mais absoluta harmonia entre todos os seus integrantes. Não há a mais remota alusão a queimadas, desmatamentos ou presença de organismos predadores. Nenhum tipo de interação desarmônica está representado. Os seres vivos, apenas plantas e animais coexistem lado a lado, cercados por solos férteis, ar puro e água abundante. Considerando que há duas concepções de natureza predominantes nas sociedades do Ocidente, percebo que meus informantes a concebem como local de bondade e harmonia, diferente da chamada Lei da selva, na qual todos lutam uns contra os outros (CHINEN, 1999).

Assim sendo, precisamos manter "o ecossistema e o ambiente sócio-cultural ${ }^{8^{a}}$,", pois integramos um, criamos o outro e precisamos de ambos. Em relação ao primeiro, usualmente somos representados como usufrutuários das belezas da natureza, ora contemplando, ora brincando ou, literalmente, flutuando em êxtase em meio as suas bonitezas, como mostra outro interessante desenho de aluno de $5^{\mathrm{a}}$ série.

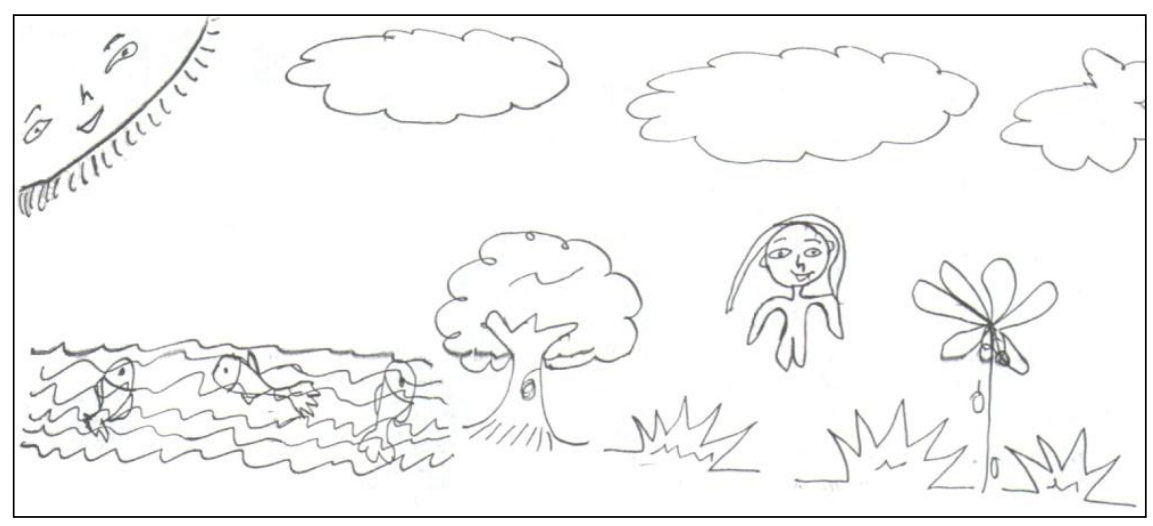

Estudos relacionados ao pensamento da população brasileira acerca do ambiente (BRASIL, 2001) referiram à tendência em concebê-lo como natureza sacralizada, já que $67 \%$ 
dos entrevistados a entendem como algo que não deve ser tocado ou maculado pelo ser humano (IBID ID), ou seja: para grande parcela dos brasileiros, ambiente é essencialmente fauna e flora. Já nossos dados não nos conduziram a pensar em exclusão humana, mas antes num enquadramento diferenciado, pois "Ambiente é um lugar onde você vive, onde você se sente bem ou mal. ${ }^{8^{\infty}}$. Tomando esta fala como protótipo, considerando que os próprios desenhos expõem o ponto de vista do observador, julgamos que a beleza tão enfatizada traduz algo que se deseja, um motivo para querer estar/ficar naquele espaço. Assim nossos sujeitos não querem ambientes degradados - reveladores de poder humano de devastar - mas sim espaços plenos em equilíbrio e harmonia, que podem assim permanecer enquanto nós, humanos, quisermos, onde podemos, conforme nossas potencialidades, nos converter naquilo que queremos ser em conformidade com nossos talentos (DUBOS, 1974). Caso não haja interesse algum em permanecer, podemos, simplesmente, nos retirar para onde for conveniente transitando do contexto natural para outros, pois “... a nossa casa, a escola, a rua,

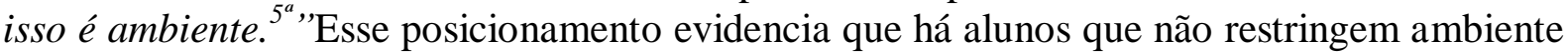
à fauna e à flora.

A abrangência do termo ambiente cria espaço para a inclusão de outros fatores, conforme denotam aspectos detectados em nossa investigação. Para nossos informantes, o ambiente é integrado por "Tudo que for feito pela natureza ${ }^{G P 2}$ ", por "Tudo o que nele pertence $^{8^{a}}$," daí a presença intensiva de fatores bióticos e abióticos como seus constitutivos, lado a lado com fatores não naturais, numa demonstração de que, aos poucos, a concepção ambiental vai se impregnando com elementos oriundos de processos antropocêntricos, conforme percebe-se em falas que citam escola, casa, campo de futebol, rua como suas partes. Pensamos que a interação social, aliada à compreensão que onde vivemos é ambiente, responde por esse estendimento dos seus integrantes a elementos evidentemente não naturais

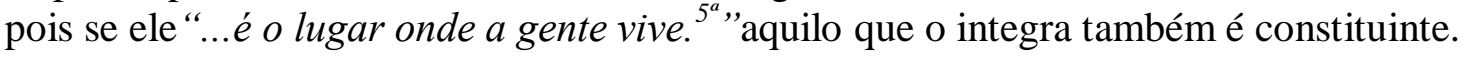

Nenhum organismo conhecido interage com a Biosfera na extensão, e diversificação, exibida por nossa espécie (CURTIS, 1977; GONÇALVES, 1996; GUATTARI, 2001). Reproduzimos, precisamos de comida e habitat, como qualquer ser vivo, mas, evidenciando nossa singularidade, também necessitamos de diversão e arte ${ }^{9}$; além de sermos geradores de culturas, religiões, filosofias e ciências. Portanto, urge preservar o ambiente, com todos seus componentes, já que “...ele representa a vida e as necessidades de quem vive nele ${ }^{G P I ~ ", ~ c o m o ~}$ bem exemplifica esta fala de aluno de $5^{a}$ série, na qual ele revela que também é parte ambiental "Deixar sua casa limpa, jogar lixo no lixo, nunca jogar bola de papel no chão $0^{5^{a}}$ ", Pode parecer incoerente que ações como "Lavar as mãos. Tomar banho ${ }^{5^{a} \text { " }}$ possam encaixarse como integrantes ambientais, pelo menos se considerando uma definição puramente ecológica. Entretanto, o conceito de ambiente transcende esta ciência, configurando-se mais como representação social, haja vista que não há consenso científico do que seja ambiente (REIGOTA, 2002).

A análise de nossos dados nos levou a concordar com Reigota (2002). Ao interagir com as concepções dos informantes, percebemos tocar a ponta de um iceberg. Evidentemente, elas refletem experiências pessoais e muito mais, pois falas e desenhos, referentes ao ambiente, também traduzem atos e situações transcorridos em contexto de socialização. Neste, conceitos, ideias e opiniões referentes à questão ambiental são discutidos, contestados, ressignificados e, por fim, incorporados ao ideário de cada cidadão. Logo, podemos captar elementos reveladores de um pensar ambiental coletivo nos posicionamentos de meus informantes. Isso responde pela presença, frequente, de elementos como árvores e florestas,

\footnotetext{
${ }^{9}$ Referência à música Comida, composição de Arnaldo Antunes, Marcelo Fromer e Sérgio Brito. Nela, os autores defendem que a satisfação das necessidades humanas transcende a fome e a sede no sentido puramente fisiológico, pois também precisamos de fatores criados por nossa espécie, como dinheiro e arte, para asseverar o bem viver.
} 
pessoas e outros animais, rios, céu ensolarado conjuntamente com preocupações do tipo precisamos do ambiente para viver nas falas de meus sujeitos, independentemente de seu grau de escolarização. São itens constituintes da imagem coletiva do que seja ambiente, daí a similitude. Trata-se de um aspecto, que remete a Serge Moscovici (1978, p. 25), quando ele diz que "Toda representação é composta de figuras e de expressões socializadas."

A concepção de ambiente, modelada a partir do que é captado interativamente, a proporção que as pessoas interagem com coisas, ações e contextos formados por, e durante, inúmeras interações cotidianas configura-se como representação social pois é "uma modalidade de conhecimento particular que tem por função a elaboração de comportamentos e a comunicação entre indivíduos" (MOSCOVICI, 1978, p. 26).

Os posicionamentos de nossos informantes são plenos em sugestões comportamentais explícitas como "Não maltratar os animais, não queimar as árvores.5", "...nunca jogar lixo no chão, sempre deixar suas casas limpas. $5^{a}$ "ou subliminares, como "se não tivesse ambiente tudo era bagunçado (Sic. $)^{5^{a}}$,, numa alusão a ambiente como sinonímia de ordem e equilíbrio, o que vai, evidentemente, requerer um posicionamento zeloso por ordem e equilíbrio de todos seus integrantes. No caso do Homo sapiens, traduzido como valores culturais, conforme bem exemplificado pela fala de nossos sujeitos, afinal "Ambiente é uma coisa que faz parte da nossa vida. Exemplo: tomar banho e lavar as mãos. ${ }^{5^{a}, "}$.

Evidentemente, é através da comunicação que tais valores circulam entre indivíduos, num processo onde, novamente, são revistos e ressignificados, pois nunca introjectamos os dados externos, seja o espaço onde vivemos, nossa cidade, a ciência ou qualquer outro elemento, como itens prontos e unívocos. Pelo contrário; eles nos estimulam a construir impressões, pautadas em crenças, credos e outros aspectos subjetivos. Não internalizamos um objeto como ele é, mas como o compreendemos. Quando nos comunicamos, passamos essa compreensão adiante e cada pessoa, ao apreendê-la, a impregna com subjetividade mas preserva a essência. E assim representações de todo e qualquer aspecto da realidade circulam entre os indivíduos (MOSCOVICI, 1978).

É provável que um construto relacionado a uma ideologia específica: o ambiente idílico, natural e aprazível, fonte de harmonia e belezas (BRASIL, 2001; MATSUSHIMA, 1991), responda por um aspecto contraditório presente nos dados analisados: a rejeição de locais que não se encaixem nesta concepção da qualidade de integrantes, mesmo que isso resulte na segregação de invasões e favelas onde, não raro, convive-se com problemas de saneamento básico, violência e desigualdades sociais. Constatamos tal exclusão, pois no panorama estruturado do ideário dos informantes inexiste lugar para qualquer forma de degradação,/conspurcação, quando se referem ao ambiente.

Como uma espécie de sonho real, o mito da natureza edênica contrapõe-se às agruras do cotidiano (CRESPO, 2003). No ambiente, idílico, existente no pensamento de nossos informantes, paz e quietude configuram-se em elementos predominantes, contrapontos à competitividade e ao stress contidos, em fartas doses, no plano concreto em que, frequentemente, em nome de interesses imediatistas, sacrifica-se, parcial ou inteiramente, o ambiente natural tão importante no imaginário de nossos sujeitos. E se no mundo real as ações preservacionistas parecem acontecer em ritmo sempre inferior ao da devastação galopante, no ideário coletivo, por outro lado, basta expurgar imagens e conceitos desagradáveis e o ambiente virtual, com todo seu cabedal de benefícios, será preservado, representando um oásis perante as adversidades do dia-a-dia, entre as quais incluem-se o desmatamento, a poluição, a ameaça da escassez de água potável, o efeito estufa e outras agressões, reais, ao equilíbrio do ambiente (CÂMARA, 2003; KLOETZEL, 2003; RICKLEFS, 1996). 
Considerando o contexto de pesquisa, afirmamos que nossas histórias de vida, imersas na vastidão da Amazônia, em meio a chuvas, mangueiras, açaizeiros, rios, peixes e lendas que falam de botos e cobras grandes como protagonistas -, também corroboram a enorme importância atribuída por nossos sujeitos ao meio natural, com o qual interagem desde a mais tenra infância. Novamente, temos a questão da representação social, já que todo esse exuberante imaginário social/regional é concebido em meio a contextos sociais plenos em discursos, discussões e comunicação que asseveram sua construção, reconstrução e manutenção (WAGNER, 1997), garantindo, portanto seu permanecer ao longo das gerações.

\section{Concepções de ambiente: consensos e contradições}

Constatamos um ponto de convergência em nossa investigação: independentemente do nível de escolarização dos informantes, sempre somos tomados, através de nosso querer, como um ponto de referência nos posicionamentos ambientais. Seja buscando beleza, meios de interação e sobrevivência, além de outras condições para nossa existência, o homem sempre está, direta ou indiretamente, no ambiente, um dado destoante de investigações nas quais os informantes não se sentiram como componentes do meio (BONOTTO, 2000; BRASIL, 2001; GUIDO, 2003; TRIGUEIRO, 2002, 2003). Outro assentimento nas vozes das crianças, adolescentes e adultos coletadas está na preocupação com a conservação de uma espécie: a nossa. E isso está inexoravelmente atrelado à preservação do restante do ambiente “...pois sem ele nós não existiríamos. ${ }^{\mathrm{GP} 1}$

Este posicionamento evidencia que o antropocentrismo, ainda que camuflado com a preservação do equilíbrio ecológico, norteia ações, e intenções, ambientais essencialmente preservacionistas, referidas pelos sujeitos conforme exemplifica esta fala de graduanda: “...é de extrema importância sua preservação, levando-nos à conscientização que se destruirmos

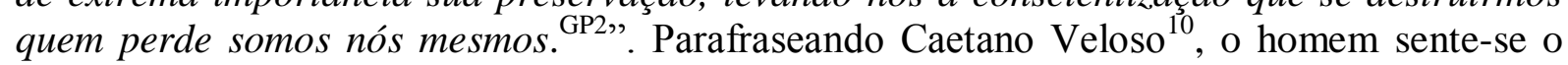
dono do sim,/preservar, e do não, destruir, diante da visão da infinita beleza/natureza. Outra fala de graduando é um rico exemplo deste modo de pensar: “...nós fazemos parte do ambiente, nós o destruímos e somente nós podemos reverter esse quadro. ${ }^{G P 1}$ ",

A concepção de homem como um ser dependente, mas soberano, integralmente, de tudo que compõe o ambiente e extremamente ávido em usufruir "de todas as facetas do prazer e da beleza que o mundo lhes revela pelos vários meios de contacto fornecidos pela natureza." (KELLER, 2002) é consensual nas exposições dos nossos informantes. Este aspecto, mais nossa responsabilidade, algo referido como praticamente inerente ao nosso interagir ambiental, já que é “...importante para o nosso corpo lugares limpos, rios limpos não poluídos e muitas coisas mais. ${ }^{5 a " ~ p e r m i t e ~ r e c o n h e c e r ~ o ~ a m b i e n t e ~ c o n c e b i d o, ~ t a m b e ́ m ~}$ consensualmente, como recurso gerenciável (SAUVÉ, 1994, 2003).

Em nenhum depoimento coletado, fomos plenamente nivelados com outros viventes. Pelo contrário: há uma intensa auto-estima atravessando a postura ideológica das crianças, adolescentes e adultos pesquisados: somos duplamente valorosos, primeiramente, por termos vida, podendo usufruir da natureza, algo que não é nem um direito, mas sim um aspecto inerente ao ato de existir, sendo efetivado, sem exceções, por todos os seres vivos, sejam vírus ou baleias; segundo porque somos seres humanos, a espécie que partiu da África para conquistar o mundo (CURTIS, 1977; LEAKEY, 1981; THORNE \& WOLPOFF, 2003; WONG, 2003b) e ocupou, de modo permanente ou provisório, todas as regiões da superfície terrestre, construindo impérios, desafiando fenômenos climáticos, criando utensílios para

${ }^{10}$ Em sua composição intitulada Luz do Sol. 
ampliar o alcance dos sentidos, e, talvez, nossa maior particularidade: complementando nossa habilidade de narrar, de relatar nossos feitos, através da invenção da escrita, possibilitando o registro de nossa existência, da nossa história na Terra, conquistando, de certa forma, a imortalidade através da perpetuação de nossas narrativas.

E o que é, afinal de contas, ambiente para nossos sujeitos? Efetivando categorização, ponderando sobre o retorno às perguntas do questionário, percebemos que as concepções constatadas não são isoladas, mas mesclam-se, imbricam-se, dialogam entre si. Apenas a ênfase em um ou outro exemplo, como a citação recorrente de ecossistemas ou ponderações tipo "...ambiente é tudo que está ao nosso redor, inclusive paisagens, cidades, ruas, monumentos, etc... ${ }^{8 a}$ ”, ou ainda que ambiente é “...onde eu moro, aonde eu passo a maior parte da minha vida. ${ }^{8 a}$ " nos conduziram a está proposição categórica já que, à semelhança de Sauvé $(1994,2002)$ e Sato (2003), concordamos que concepções arquetípicas do ambiente originam-se de posicionamentos e reflexões ante a realidade sendo "...eminentemente complementares e podem ser combinadas em diversos caminho.” (SAUVÉ, 2002, p.4).

Entre os 181 informantes, constatamos quatro concepções com características especificas: $O$ Manancial da vida: compreende tudo, sem exceções, que é oriundo da própria natureza e assegura a vida. 65 informantes $(35,9 \%)$ concebem assim o ambiente. Esta concepção foi mais frequente, respectivamente, nos estudantes do $3^{\circ}$ ano, quinta e oitava séries. Onde vivo, estou e vou: é o lugar onde vivemos, interagindo com outros organismos, incluindo nossa espécie, e o restante do meio. 70 informantes $(38,7 \%)$ compreendem o ambiente desta maneira. Predominou, respectivamente, entre estudantes de Graduação ${ }^{\mathrm{GP}}{ }^{1}$, oitava e quinta séries. É o espaço que nos envolve: trata-se da extensão não definida, e todos seus componentes, que nos circula. Para 28 informantes $(15,5 \%)$, isso é ambiente. Foi mais frequente entre estudantes de graduação, prevalecendo entre as concluintes ${ }^{\mathrm{GP} 2}$, sendo a terceira posição ocupada pelos discentes da oitava série. Mistas: congregam elementos das três categorias. Presentes entre 18 informantes $(9,9 \%)$. Prevaleceu entre os graduandos, predominando nas concluintes ${ }^{\mathrm{GP} 2}$, cabendo a terceira posição aos alunos de oitava série.

Considerando a questão da complexidade, não constatamos distinções que permitissem estabelecer hierarquização. A ideia de uma gradação estruturada a partir de concepções mais simples rumo àquelas mais sofisticadas, possivelmente seguindo a própria complexidade inerente aos diferentes momentos de escolarização, foi logo descartada quando percebemos que os elementos componentes das concepções: as impressões acerca do ambiente, baseadas em referências a "Plantas, cidades, seres humanos ${ }^{8^{a}}$ " ou ao "ambiente escolar, de trabalho, de descanso, de lazer, como bosques, praças ${ }^{G P l ”, ~ n a ̃ o ~ s e ~ r e s t r i n g i a m, ~ e m ~ t e r m o s ~ d e ~}$ ocorrência, a uma série ou outra, mas se manifestavam em todas elas, evidenciando a circulação de uma representação de ambiente socialmente estruturada no âmago da existência cotidiana, no transcurso da comunicação entre os cidadãos (MOSCOVICI, 1978). Esta representação circula entre pessoas e grupos sociais, é significada e ressignificada obviamente influenciada pelos diferentes contextos de escolarização dos sujeitos -, mas tem seu cerne preservado e este, ao aflorar nos posicionamentos dos sujeitos, responde pelas similaridades da compreensão de ambiente de crianças, adolescentes e adultos.

Dentro do contexto delineado por nossos sujeitos, um olhar, independente de provir de uma criança, adolescente ou adulto, ao eleger "Casa, rua, escola.. ." $^{a}$ como exemplos de ambiente, não revelaria mais sofisticação que outro que optasse por "mar, terra, os planetas $^{G P 2}$ ". Ou seja: uma concepção não é melhor do que a outra; ambas são reveladoras do pensar de parte, de uma coletividade, acerca de uma temática. Ambas propiciam detectar representações simbólicas, atribuições de princípios, qualidades, saberes e convicções. Todos 
esses elementos podem se exibir por meio de inter-relações sociais, como o ato de narrar, seja de modo real ou idealizado (GUEDES, 2003).

No universo do dia-a-dia, à semelhança de seres palpáveis, as representações sociais, pensamentos coletivos construídos reflexivamente, a partir de qualquer temática com que interagimos, como a ambiental, transitam livremente, intercruzando-se e concretizando-se de modo contínuo, ganhando vida através de gestos, frases, palavras e outras formas de expressão, frutos da própria dinâmica social (MOSCOVICI, 1978).

Obviamente, trata-se de um quadro situacional onde elementos do ambiente, num processo cíclico, geram influências capazes de alterar as representações que dele se constróem. Em nossa investigação, dois elementos revelaram-se relevantes nas concepções detectadas: a mídia e o processo ensino e aprendizagem vivenciado em âmbito escolar.

Tomando a ideia do Manancial de Vida. Dentre as quatro concepções, é a mais pautada em subjetivações de preceitos ecológicos. Sua frequência foi mais elevada nos sujeitos que vivenciam, aulas de conteúdos específicos de Ecologia. Cabe destacar que tópicos dessa ciência também integram o programa da Sexta Série e, de modo subliminar, estão presentes nas demais séries do Ensino Fundamental, certamente subsidiando a elevada incidência desta concepção em alunos de oitava série.

Provavelmente, o distanciamento entre estudantes e conteúdos ecológicos nas Graduações averiguadas, onde são abordados de forma bastante sintética, como fundamentos para a percepção das bases biológicas do contexto educacional, responda pelo menor status dessa concepção entre os discentes desse nível de escolarização. No entanto, a ausência de exclusão do Manancial de Vida, e de qualquer outra concepção, entre nossos sujeitos faz pensar tanto na relevância dos conceitos ecológicos no contexto social (BRASIL, 2001), quanto na sua presença freqüente na mídia.

Desde os anos 70 do século passado, reportagens centradas em imagens e sons de santuários exóticos e selvagens tiveram, gradativamente, seu espaço ampliado nas grades de programação de TVs públicas e por assinatura (CRESPO, 2003; TRIGUEIRO, 2003), bem como em revistas semanais de interesses gerais (BARROS, 2001). Mesmo propagandas veiculadas por emissoras de TV passaram a utilizar imagens da natureza visando a estimular o consumo de produtos diversificados (AMARAL, 1997). Obviamente, nossos 181 informantes não devem se diferenciar, significativamente, dos "...90\% da população brasileira que se informam sobre meio ambiente (e eu ousaria dizer sobre quase tudo) através da televisão." (CRESPO, 2003, p. 65).

Assim, o ambiente idílico “...que mantém um equilíbrio ambiental. ${ }^{C, ", ~ c u j o ~ e x e m p l o ~}$ pode ser a "Floresta Amazônica GPI", presente na representação de um Manancial da vida possivelmente foi gestado a partir da fusão entre o discurso propagandeado pelos meios de comunicação e a práxis escolar. Logo, pode se apresentar em estudantes que não vivenciam aulas de Ecologia, pois a construção do conhecimento extrapola as fronteiras das instituições oficiais de ensino, podendo, igualmente, sofrer influências de diferentes instâncias culturais aptas a modelar a vida cotidiana (AMARAL, 1997).

Nesse contexto, nossos sujeitos se sentem parte do ambiente. Esta tendência apareceu em todas as concepções, principalmente naquela que versa ser o ambiente Onde vivo, estou e vou, construída a partir de falas que salientam que ele é importante "Porque precisamos dele para nossa sobrevivência e devemos cuidar dele a todo momento. ${ }^{G P 2}$ ", afinal de contas “..é de extrema importância a sua preservação, levando-nos a conscientização que se destruirmos quem perde somos nos mesmos ${ }^{G P 2}$ ". 
A acentuada preocupação com os rumos ambientais de estudantes de quinta e oitava séries, expresso pelo significativo enquadramento de seus posicionamentos nesta concepção, reveladora do entendimento que nosso existir depende do que é natural, mas também transcorre em outros contextos, sugere duas coisas: primeiro, que a escola está abrindo espaço para uma percepção de ambiente mais holística: de que este não é só natureza; segundo, que a proliferação de programas centrados em educação ambiental, em mídias diversas, parece estar levando crianças e adolescentes a preocuparem-se com as questões ambientais, algo já perceptível em pessoas "mais velhas" (CRESPO, 2003).

\section{Particularizando ambientes concebidos}

Averiguando as concepções obtidas do pensar de nossos sujeitos, lançando olhares e reflexões tanto para as falas dos nossos sujeitos quanto ao referencial teórico estruturado na investigação, constatamos tendências que nos levaram a propor categorizações particulares para o ambiente:

$O$ ambiente universal: seria integrado por todos os fatores biológicos, químicos e físicos, bem como por suas interrelações, excluindo-se, no entanto, as desarmônicas, totalmente ausentes das ponderações dos nossos informadores, substituídas por uma coexistência pacífica entre seres vivos e fatores físico-químicos. Quanto a suas dimensões, seriam amplas, mas, para a maioria dos sujeitos, definidas pois seriam restritas aos limites de nosso planeta. Isso é mais uma evidência da influência de informações ecológicas em seus entendimentos, pois a vida, como a compreendemos, está limitada às condições de luminosidade, oxigenação, temperatura e disponibilidade de água líquida encontradas na Terra (CURTIS, 1977; ODUN, 1988; PURVES et al, 2002; RICKLEFS, 1996).

Assim, o grande ambiente seria a própria Biosfera. Entretanto, conforme apregoam os preceitos ecológicos, nenhum integrante de uma totalidade está isolado das influências de seu entorno, logo nosso planeta interfere na dinâmica do espaço no qual está incluso: o próprio universo, e certamente recebe intervenções cósmicas em seus processos. Esta perspectiva pode ser o motivo da inclusão de outros planetas, enfim, da extrapolação dos limites ambientais para além das fronteiras terráqueas por parte de alguns sujeitos, pois ambiente "...é o lugar onde se encontram as pessoas ou os animais e tudo o que existe no universo ${ }^{8^{a}}$ ",

$O$ ambiente do homem: está incluso no universal, sendo constituído por estruturas específicas onde vivenciamos nosso existir: as cidades com suas casas, escolas, ruas e praças, tendo elementos culturais e tecnológicos a envolvê-lo como, numa analogia com a célula, uma membrana semipermeável. Por ser dependente do primeiro para sua sobrevivência, o ambiente do homem precisa cuidar do ambiente universal, que necessita ser conservado, pois, num processo similar à permeabilidade seletiva, nele buscamos obter tudo o que assevera nossas vidas.

Assim água potável, ar puro, animais e vegetais úteis (aos nossos interesses), petróleo, ouro e pedras preciosas, solos férteis podem entrar em nosso espaço onde serão consumidos das formas mais diferenciadas. Por conta dessa necessidade, advém nossa preocupação em resguardar este grande manancial, através de campanhas e ações intensificadas, desde os anos sessenta do século passado, propondo um gerenciamento de recursos para o presente e para as gerações vindouras. Isso vem ocorrendo por uma percepção, crescente, da fragilidade dos processos biosféricos ante nossa voracidade espoliativa, haja vista que os mesmos processos culturais e tecnológicos propiciadores das formas de apropriação, e relação, com os elementos naturais, ainda concebidos essencialmente como recursos, favorecem novas modalidades de 
consumo graças a um dos caracteres diferenciadores de nós, Homo sapiens, dos demais viventes: nossa sede infinita por descobertas e conhecimento.

\section{ALGUMAS CONSIDERAÇÕES}

Para nossos sujeitos, o ambiente ainda é predominantemente biofísico e extremamente amplo, tanto que pode conter outros planetas, ainda acolhendo nossas casas, ruas, enfim nossas cidades. Meus informantes enquadram-se, portanto, ao Homo sapiens, como integrantes do ambiente, mas nunca no mesmo nível dos outros seres vivos, já que seus posicionamentos evidenciam o homem e demais viventes numa distinção evidente. Somos superiores e existimos em um nicho incluso dentro do espaço natural: um ambiente antrópico, onde mantemos nosso estilo de viver. Neste nicho construído, exploramos o que se encontra no Espaço que nos envolve, e é útil a nossos interesses, filtrando, através de cultura e tecnologia os recursos de Gaia, a mãe natureza. Esse, por sinal, seria o grande motivo da conservação do ambiente natural.

Percebemos o ambiente de ensino e aprendizagem como um nicho privilegiado para lidar com essas questões, estimulando à maturação de criticidade ante abordagens de ambiente veiculadas pela mídia reforcem a ideia que ambiente restringe-se à fauna, flora e ecossistemas quase intocados ou com pouca interferência humana. Além disso, o âmbito escolar pode ser um espaço construtor do reconhecimento, por todos nós, da necessidade de assumirmos nossa integração com a biosfera, nossa casa, nosso único endereço no grande ambiente do Universo (BOFF, 2003a, 2003b), o local Onde vivo, estou e vou, para que a satisfação de nossas necessidades não se converta em uma fonte de desequilíbrio e desarmonia que certamente nos vitimizará.

Entretanto, isso requer que a escola supere uma práxis pautada na mera reprodução acrítica de saberes (ARAGÃO, 2000). Carece a esta instituição, independentemente de níveis de escolarização, sintonizar-se com as contradições da atualidade, como querermos preservar o meio natural, nosso Manancial de Vida, sem abrir mão do privilégio de usá-lo a nosso bel prazer, e contribuir, conjuntamente a outros setores sociais, com ações e reflexões, para que, apesar do antropocentrismo - tendência difícil de abandonar -, comecemos a elaborar estratégias de equilíbrio de nossas necessidades consumistas com o respeito aos ritmos planetários.

Tais ações não devem desqualificar o homem como vilão depredador ou candidato a Deus, detentor do poder de conservar ou destruir o ambiente, mas pautar-se pelo que realmente somos: seres com especificidades - aliás como qualquer organismo - tão interdependentes do contexto planetário como qualquer outra forma de vida (CAPRA, 2003; LUTZEMBERGER, 2001).

O Homo sapiens é um ser capaz de estabelecer concepções a partir do que vê, percebe, cria. Durante esta investigação, partimos da noção de concepção de ambiente e percebemos que está se configura em algo mais complexo: a representação social. Assim a ideia do Manancial de vida, local Onde vivo estou e vou, composto pelo Espaço que nos envolve carrega consigo toda a subjetividade socialmente estruturada, a partir de diálogos, discussões e outras modalidades de comunicação. A representação de ambiente trás em seu bojo tanto a peculiaridade do individuo quanto o ideário coletivo acerca desta temática. Certamente, os valores representativos da fusão destes aspectos, ou seja, as ideias de cuidado, de conservação e o próprio modo de conceber, e se posicionar, no ambiente podem ser valorosos coadjuvantes 
em Educação em Ciências e Educação Ambiental, já que as ações partiriam do que os sujeitos pensam, sentem, compreendem no, sobre e para o ambiente.

Defendemos, concordando com Reigota (2002), que um passo essencial na educação ambiental seja identificar as concepções de ambiente. As representações sociais desse tema expõem uma gama de aspectos, desde aqueles centrados em experiências do dia-a-dia até os advindos de conhecimentos científicos, sem esquecer elementos políticos, ideológicos, místicos, conceitos e preconceitos que se mesclam, de forma única (MOSCOVICI, 1978), compondo aquilo que se pensa, ambientalmente falando, bem como uma base para intervenções eficientes.

Ações que conduzam à comunhão com cada vivente, parceiros na existência compartilhada neste colossal organismo chamado Terra, palco de nossos vidas, cenário onde nossas interações, e contradições, interferem, e sofrem interferências, de cada elemento -

biótico ou abiótico, natural ou antrópico - presente/componente neste planeta, tão pequeno ante o contexto universal, mas tão grandioso por configurar-se naquilo que propicia nossa identidade, no que assegura nosso existir no tempo e no espaço, em nossa, até então e sabe-se lá até quando, única ilha no oceano cósmico.

\section{BIBLIOGRAFIA}

AMARAL, M.B. (Tele)natureza e a construção do natural: um olhar sobre imagens de natureza na publicidade. IN: OLIVEIRA, D.L. (org.) Ciências nas salas de aula. Porto Alegre: Mediação, 1997. p.83 a 96

ARAGÃO, R.M.R. Uma interação fundamental de ensino e de aprendizagem: professor, aluno, conhecimento. In: Schnetzler, R.P. \& ARAGÃO, R.M.R (orgs) Ensino de Ciências: fundamentos e abordagens. Campinas, R.Vieira Gráfica e Editora Ltda. 2000. p. 82-98.

ARRUDA, A. Representações sociais e movimentos sociais: grupos ecologistas e ecofeministas do Rio de Janeiro. In: MOREIRA, A.S.P. \& OLIVEIRA, D.C. (orgs) Estudos interdisciplinares de representação social. $2^{\mathrm{a}}$ ed. Goiânia: AB, 2000. P. 71 a 86.

ATLAN, H. As finalidades inconscientes. IN THOMPSON, W.I. (org.) Gaia: uma teoria do conhecimento. São Paulo. Gaia. 1990. p.103 a 119.

BADIN, L. Análise de conteúdo. Lisboa: Edições 70, 1977

BATESON, G. Os homens são como a planta: a metáfora e o universo do processo mental. In: THOMPSON, W.I. (org.) Gaia: uma teoria do conhecimento. São Paulo. Gaia. 1990. p.35 a 44.

BRASIL. Ministério do meio ambiente \& Instituto Superior de Estudos da Religião $O$ que o brasileiro pensa do meio ambiente. 2001b (Pesquisa de opinião pública)

BOFF, L. Ecologia e espiritualidade. In: TRIGUEIRO, A. (org.) Meio ambiente no século 21: 21 especialistas falam da questão ambiental nas suas áreas de conhecimento. Rio de Janeiro: Sextante, 2003a. (p. 34 a 43)

$2003 b$.

Ethos mundial: um consenso mínimo entre os humanos. Rio de Janeiro: Sextante, 
BONOTTO, D.M.B. Conceitos e valores em educação ambiental: uma experiência com alunos que não conseguiam juntar área verde $e$ cidade. Em http://www.rc.unesp.br/ib/cea/holos/MS-052000.htm. Visitado em 06/03/2003

CABRAL, M. C. R. O paradigma mecanicista e a educação ambiental nas diretrizes curriculares oficiais de ciências do estado do Pará. Campinas: Faculdade de EducaçãoUNICAMP, 2000. 121P. (Dissertação de Mestrado).

CÂMARA, I.G. Problema ou solução? In: TRIGUEIRO, A. (org.) Meio ambiente no século 21: 21 especialistas falam da questão ambiental nas suas áreas de conhecimento. Rio de Janeiro: Sextante, 2003. p.158 a 169.

CAPRA, F. Alfabetização ecológica: o desafio para a educação do século 21. In: TRIGUEIRO, A. (org.) Meio ambiente no século 21: 21 especialistas falam da questão ambiental nas suas áreas de conhecimento. Rio de Janeiro: Sextante, 2003. (p. 18 a 33)

CHINEN, J. O ambiente e o ensino de Ciências: a fala do professor como um dos elementos de sua formação continuada. São Paulo. Unicamp. Faculdade de educação. 1999. (Dissertação de Mestrado).

CHIZOTTI, A. Pesquisa em ciências humanas e sociais. São Paulo: Cortez, 1991 (Biblioteca da educação. Série 1. Escola. V.16).

COIMBRA, J.A.A. O outro lado do meio ambiente. São Paulo: CETESB, 1985.

CRESPO, S. Uma visão sobre a evolução da consciência ambiental no Brasil nos anos 1990. In: Meio ambiente na idade mídia. In: TRIGUEIRO, A. (org.) Meio ambiente no século 21: 21 especialistas falam da questão ambiental nas suas áreas de conhecimento. Rio de Janeiro: Sextante, 2003. p.58 a 73.

CURTIS, H. Biologia. Rio de Janeiro. Guanabara Koogan. 1977.

DIAS, G. F. Os quinze anos da Educação Ambiental no Brasil. Em Aberto, Brasília, v.10, nº 49, Jan/Mar 1991. Págs. 3 a 14.

DUBOS, R.J. Um animal tão humano: como somos moldados pelo ambiente e pelos acontecimentos. São Paulo. Melhoramentos. Ed. da Universidade de São Paulo, 1974.

FONTANA, K.B. et al. A concepção de meio ambiente de alunos do curso de pedagogia a distancia e a importância da mediação tecnológica - dificuldades e perspectivas. [Centro de Educação à Distância. Universidade do Estado de Santa Catarina. Brasil], 2002. Em http://virtual.udesc.br/html/artigos_professores/profs_ema.htm visitado em 20/04/2003

GONÇALVES, C.W.P. Os descaminhos do meio ambiente. $5^{\text {a }}$ ed. São Paulo. Contexto. 1996.

GUATTARI, F. As Três Ecologias. Campinas, SP: Papirus, 2001.

GUEDES, A. S. A representação mental e social do portador da síndrome da dependência do álcool. Revista do Centro Sócio-Econômico. Universidade Federal do Pará , v.1, nº1, jan./jun.2003 (Pág. 29 a 47)

GUIDO, L.F.E. Os meios de comunicação social e sua influência na representação de ambiente em alunos do ensino fundamental [Universidade Federal de Uberlândia]. Em http://www.clacso.edu.ar/ libros/anped/1603P.PDF visitado em 15/07/03.

GUIMARÃES, M. Educação ambiental: no consenso um embate? Campinas, SP: Papirus, 2000 . 
KELLER, H. Três dias para ver. Núcleo de Informática Biomédica. Universidade Estadual de Campinas. Revista cérebro e mente. No 16 - 31. Dezembro 2002 - Abril 2003. Disponível em http://www.epub.org.br/cm/home.htm visitado em 15/01/03

KLOETZEL, K. O que e meio ambiente. São Paulo: Brasiliense, 2002.

LEAKEY, R. A evolução da humanidade. São Paulo. Melhoramentos. 1981

LUTZEMBERGER, J. Hipótese Gaia. “ A Terra é um ser vivo. [2001] Disponível em http://www.arvore.com.br. Visitado em 13/03/2003.

MEYER, M. A. A. Educação Ambiental: uma proposta pedagógica. Em Aberto, Brasília, ano 10, nº 49, jan./ mar. 1991. (P. 41 a 56)

MOSCOVICI, S. A Representação social da Psicanálise. Rio de Janeiro: Zahar Editores, 1978.

ODUM, E. Ecologia. Rio de Janeiro. Guanabara Koogan S.A., 1988.

OKAMURA, C. As representações sociais do meio ambiente de professores de Educação Ambiental [Anais do $20^{\circ}$ Congresso Brasileiro de Engenharia Sanitária e Ambiental-1999] http://www.saneamentobasico.com.br/materia/estudos/files/textos98/VI-079.doc visitado em $20 / 03 / 2003$

PENTEADO, H.D. Meio Ambiente e Formação de Professores. São Paulo: Cortez, 1997.

PIMENTEL, R.S.S. \& BORDEST, S.M.L. A percepção ambiental das pessoas que ocupam as áreas próximas à foz do córrego Prainha. [Revista V.006 nº 010 Jul/Dez 1997. Universidade Federal de Mato Grosso. Brasil]. Em http://www.ufmt.br/revista/arquivo/rev10/percepcao_ambiental.html Visitado em 20/04/2003

PURVES, W.K. et al. Vida, a ciência da Biologia.6.ed. Rio Grande do Sul: Artmed Editora, 2002.

REIGOTA, M. O que é Educação Ambiental. São Paulo: Brasiliense, 1996. Coleção Primeiros Passos.

REIGOTA, M. Meio ambiente e representação social. São Paulo: Cortez, 2002. Questões de nossa época.

RICKLEFS, R.E. A Economia da natureza. Rio de Janeiro. Guanabara Koogan S.A., 1996.

SANTANA, A.R. et al. O meio ambiente no pensar de alunos do ensino médio do NPI/UFPA. Anais da 55ª reunião anual da SBPC. Recife/PE. Julho de 2003. (Cd-rom)

SATO, M. Educação Ambiental. São Carlos: Rima, 2003.

SAUVÉ, L. L’Éducacion Relative À L'Environnement: Une Diversité de Conceptions. In: Sauvé, L. Pour Une Éducacion Relative à L'Environnement. Montreal: Guérin, 1994. Cap.1. p. 9-37.

SAUVÉ, L. Educação Ambiental e Desenvolvimento Sustentável: Uma análise complexa. Em http://www.ufmt.br/revista/arquivo/rev10/educacao_ambiental_e_desenvolvim.html acesso em 20/04/2003.

THOMAS, K. O Homem e o Mundo Natural: Mudanças de Atitudes em Relação às Plantas e aos Animais, 1500-1800. São Paulo: Companhia das Letras, 1988.

THORNE, A.G. \& WOLPOFF, M.H. A evolução multirregional dos seres humanos. Edição Especial Scientific American Brasil. No 2, Novembro de 2003 (Pág. 48-55) 
TRIGUEIRO, A. $O$ que o brasileiro pensa sobre meio ambiente. [2002] Em www.arvore.com.br Visitado em 13/03/2003

Meio ambiente na idade mídia. In: TRIGUEIRO, A. (org.) Meio ambiente no século 21: 21 especialistas falam da questão ambiental nas suas áreas de conhecimento. Rio de Janeiro: Sextante, 2003. p.74 a 89.

VERNIER, J. O Meio Ambiente. $2^{\text {a }}$ ed.Campinas, SP: Papirus, 1998.

VIEIRA, L. Algumas considerações sobre o conceito de natureza e crise ecológica. [2001] em www.arvore.com.br Visitado em 17/05/2003

WAGNER, W. Descrição, explicação e método na pesquisa das Representações Sociais. In:

GUARESCHI, P.A. \& JOVCHELOVITCH, S. (orgs.) Textos em representações sociais. $2^{\mathrm{a}}$ ed. Petrópolis, RJ: Vozes, 1997. (Pág. 149 a 186) 